\title{
The Effectiveness of MALT on Vocational College English Teaching
}

\author{
Rui Wu \\ English Department, Beijing Information Technology College, Beijing, China
}

\begin{abstract}
With the fast development of modern information technology, mobile terminals and their applications, an increasingly number of teachers come to realize it may be probable to improve teaching quality by using mobile terminals. However, there is no solid data so far in literature that support the effectiveness of MALT (Mobile Assisted Language Teaching). Therefore, this article is dedicated to prove its effectiveness on vocational college English teaching using Moso Teach as a platform. It is found that MALT has effectively improved teaching quality. The students who used Moso Teach more have achieved greater progress. But poor students are not active in using the mobile teaching platform. As a result, it is suggested that teachers should integrate MALT in their English teaching on condition that teaching is carefully designed, and teachers should try to help poor students change their attitudes toward using mobile teaching platforms.
\end{abstract}

Index Terms-MALT, vocational college, English teaching

\section{INTRODUCTION}

With the development of modern information technology, the teaching mode of higher education has made a great leap forward. Since 2012, web-based teaching has risen rapidly all over the world. Shipments of mobile terminals around the world reached nearly 1 billion units in 2013, triple the number of PCs. As of January 2015, the total number of mobile devices connected to the Internet worldwide exceeded 7 billion. In the fourth quarter of 2017, the smart terminals in China reached 1.42 billion, each carrying over 40 APP units on average (China Industry Information Net, 2018). Mobile terminal has replaced PC as the main carrier of network teaching, forming a new teaching form -- mobile teaching. At the same time, the application service for mobile online teaching is also being perfected, and various educational application software has mushroomed and spread rapidly. Many teachers are keenly aware that these applications can be used to improve teaching quality, so they have made many useful explorations.

Post-90s generation college students, especially higher vocational students, are willing to accept novelties and have a strong dependence on mobile phones. According to the characteristics of students, many teachers began to use mobile applications to assist classroom teaching in practice. But mobile assisted teaching is original. By using MALT, the physical environment of teaching and the way of spreading knowledge have both changed compared with traditional teaching methods. Therefore, most teachers are eager to know whether and to what extent mobile assisted teaching can improve teaching quality so that they can decide whether and how to use it.

\section{LITERATURE REVIEW}

\section{A. Basic Concepts}

Mobile learning is a learning mode in which learners can obtain learning resources, complete learning tasks and communicate with peers and teachers at any time and place through mobile devices such as smart phones and tablet computers ( $\mathrm{Su} \& \mathrm{Li}, 2016)$. Mobile learning should include at least the following four elements: mobile learners, using mobile devices, connecting with mobile networks, and learning in mobile situations (Ye, 2004). Mobile assisted teaching is that teachers use mobile learning software to assist classroom teaching. It complements and serves classroom teaching, promoting teaching quality. This article focuses on mobile assisted language teaching (MALT), which expects to raise the English language teaching quality.

Generally speaking, mobile learning applications can be divided into two categories. One is a comprehensive application-oriented app with functions of uploading resources, assigning tasks, interactive discussions, evaluation and testing, such as WeChat group, QQ group and Moso Teach, etc. The other is a task-driven application, which aims at improving particular ability such as listening, speaking, reading and writing. Cutting-through Hundred Words, Zhimi Word Memorization and Interesting Dubbing in English, etc., belong to the second category.

Moso Teach is one of the most popular mobile learning applications for teachers. It was introduced into the market in 2014 and is a cloud teaching tool that integrates cloud computing, big data, mobile connectivity and other technologies and is closely integrated with classroom teaching. Teachers can independently upload teaching related materials, which makes it more targeted for school teaching. Through Moso teach, teachers can assign homework tasks, organize activities such as discussion, questionnaires and brainstorming, etc. Those activities, which can be carried out anytime and anywhere, systematically integrate fragmented teaching resources and learning time, creating a favorable learning environment. Every time a student completes a particular task, he or she will get the corresponding experience points, 
and the learning results can be evaluated by three parties of machines, teachers and classmates, thus improving the learning enthusiasm of students. Moso Teach has a certain management function. It can automatically track the learning progress and evaluation of each student, and the results are fully presented by big data. It enables teachers to understand the learning status of students in a timely and scientific manner, thus realizing intelligent teaching based on big data.

\section{B. Theoretical Basis}

Constructivism, the Affective Filter Hypothesis and Ubiquitous Learning are the three theoretical bases of mobile assisted teaching.

Constructivism is a theory of knowledge and learning developed from philosophy, psychology and anthropology. It was put forward by Swiss psychologist J. Piaget, who advocates that the essence of learning is a process of knowledge construction for students, in which learners construct new knowledge on the basis of existing old knowledge with the help of others (including teachers and learning partners) and necessary learning materials under certain circumstances. Constructivists believe that learning has the characteristics of enthusiasm and initiative, and advocate learner-centered learning under the guidance of teachers. It not only emphasizes the cognitive subject status of learners, but also does not ignore the guiding role of teachers. Therefore, it is in line with the educational concept of mobile assisted teaching, where teachers upload courseware, micro-lectures, videos, test questions and other learning resources in the application, organize activities and assign tasks to guide students to study. Students give full play to their subjective initiative, browse resources in the mobile learning environment, complete learning tasks such as homework, tests and group work in application, thus acquiring new knowledge and skills. Therefore, mobile assisted teaching is a model for the application of constructivism.

In the 1980s, American linguist S. D. Krashen put forward his famous Five Hypotheses. The "affective filter hypothesis" points out that the process of second language acquisition is influenced by many affective factors. Language input must be filtered through emotion before it can be absorbed. Krashen believes that the affective factors that affect language acquisition are motivation, personality and emotional state. Emotional state mainly refers to anxiety and relaxation. People with strong anxiety have high emotional barrier and less input. On the contrary, it is easier to get more input. In the traditional class, some students are always in a state of high tension due to personality reasons or poor academic performance, which affects their learning result. However, in mobile-assisted teaching, students' learning partners are machines that act as mobile terminals and do not laugh at students, so the anxiety of learners will be greatly relieved and the influence of anxiety factors on language acquisition will be minimized.

Ubiquitous learning (U-learning) refers to an intelligent learning environment where people use any terminal at any time and at any place. It is different from learning in specific places such as schools and libraries. Ubiquitous learning has the following basic elements: firstly, it needs the support of ubiquitous learning environment; secondly, it is learnercentered and focuses on learning tasks; thirdly, it is a natural or spontaneous behavior and learners actively participate in it; lastly, the learners will focus on the learning tasks and objectives themselves, rather than the peripheral learning tools or environmental factors. U-learning is the embodiment of a learning state which integrates various kinds of learning such as digital learning, mobile learning and lifelong learning. It is an inevitable development stage of learning. Mobile learning is one of the important means and concrete forms of ubiquitous learning (Pan, et al., 2010).

The above three theories provide theoretical support for the development of mobile assisted instruction. Teachers guide students to carry out ubiquitous learning purposefully and systematically through mobile terminals and during this process students construct new knowledge. Because the students get rid of the limitation of time and space in their study and their emotional anxiety is greatly relieved, their enthusiasm and initiative are further brought into play. All of those contribute to promoting students' language learning effect.

\section{Current Research Findings}

A broad literature review was done by searching in the databases Web of Science and ScienceDirect. It was found that in recent years, mobile assisted teaching has become increasingly popular in higher education home and abroad and a large number of researchers explored MALT from various aspects.

1. Research on the Functions of Mobile Applications

Some scholars focused on the functions and features of mobile applications, such as Wechat, podcasting, Duolingo, WhatsApp, etc. In 2014, a group of English teachers in Guang Dong Jiangmen Polytechnic College explored the feasibility of applying WeChat in their college English teaching (Guo \& Guo, 2015). The research group believes that WeChat has the characteristics of dissemination, interactivity, equality and friendliness, making up for the traditional classroom teaching. They put forward three major implementation strategies: opening WeChat platform, establishing chat groups and managing at different levels. Cavus (2016) studied an intelligent app that promotes English pronunciation, and found it makes learning easier and more enjoyable than the traditional learning methods. He (2017) studied micro-mobile teaching for college English based on Apps. She found that the popular applications, such as Bacon Vocabulary Expansion, Cutting-through Hundred Words and Cloud Words, have diversified the ways of learning vocabulary. Their stepped vocabulary learning tasks are applicable to students with different vocabulary bases, which can reduce boredom and improve the efficiency of vocabulary learning.

These researchers generally believe that the use of mobile-assisted teaching software can greatly stimulate learning interest and enhance learning motivation. At the same time, they also put forward some problems that should be paid 
attention to in carrying out mobile teaching, such as strengthening the learning function of software and timely followup of teaching control measures (Guo \& Guo, 2015). Besides, Souza, et al. (2017) found that some applications, such as Duolingo, cannot supply the need for communication and interaction that make language learning more effective although they aim at carrying the learning beyond the borders of classrooms by a frequent contact with the target language.

\section{Research on Students' Attitudes toward Mobile Learning}

Some researchers also investigated the students' attitudes towards mobile based learning, their learning status and the factors affecting learning. Al-Emran, et al. (2016) made an investigation among students and teachers about their attitudes toward using mobile learning (M-learning) in higher education of Oman and UAE in the Arab Gulf region. Findings revealed significant differences among students with regard to their country and age. At the same time, it pointed out that M-learning could be one of the promising pedagogical assistances in tertiary education within the Arab Gulf countries. Saidouni, et al. (2016) explored teachers' and students' attitudes toward the effectiveness of MALL (Mobile Assisted Language Learning). It was found that they not only have positive attitudes toward MALL, but also agreed on its potential and regarded it as a promising approach for teaching EFL. Manman Ding's (2017) research showed that college students generally gave positive comments on mobile learning. Self-management ability is the main factor that affects their mobile learning result. She proposed strategies to optimize mobile learning based on smart phones from the aspects of individual learners, learning resources, learning environment and technical support.

3. The Impact of Mobile Apps on Teaching Quality

Other researchers made literature research to investigate the impact of mobile applications on education, especially on language teaching. Yao-Ting Sung (2016) performed a meta-analysis and research synthesis of the effects of integrating mobile devices in teaching and learning. Analysis of their empirical research revealed that the overall effect of using mobile devices in education is better than when using desktop computers or not using mobile devices as an intervention. Khalitova, et al. (2016) made a case study of using mobile application Instagram and found Instagram was efficient as an online educational environment for learning EFL.

Some of the researchers went further to put mobile devices into their teaching practice, which yielded some interesting results and seemed to elicit more diverse and innovative educational methods. Ruofei Wang (2018) conducted a questionnaire survey on the two classes after implementation of mobile teaching, and found that $95 \%$ of the students were fond of mobile teaching mode. The students thought learning by mobile phones was interesting, especially when they could get timely feedback and encouragement after completing a task, so their learning enthusiasm was greatly stimulated. Zhanpeng Xu, et al. (2018) tried to apply mobile Internet technology in hybrid teaching. They selected Moso Teach as a hybrid teaching tool and carried out in-depth mobile, cloud, big data and intelligent teaching based on constructivism, creating a mobile internet plus class, integrating teaching, learning and management. Some English teachers have also practiced mobile assisted instruction. Jun Zhou (2017) applied a mobile learning platform to his English teaching in higher vocational colleges, believing that the application of mobile learning broadens teaching resources, optimizes learning content and promotes the informatization level of English education in higher vocational colleges. On the other hand, mobile learning, as a novel learning mode, breaks the traditional teaching phenomenon of emphasizing knowledge and neglecting practical training. It promotes the interaction between teachers and students in a convenient way and helps teachers keep abreast of students' learning situation, thus improving teaching quality.

4. The Challenges of MALT

However, the literature research also revealed a bit of uncertainty about the effectiveness of mobile assisted education, and a couple of challenges have been identified as well. Min Liu, et al. (2014) made an investigation of iPod Touch used by English learners in the United States. The results revealed the iPod Touch provides differentiated instructional support, and extends learning time from classroom to home, but it exerts a great time demand on teachers and needs professionally trained and dedicated support staff. A note-worthy finding of Yao-Ting Sung (2016) is that game-based learning did not achieve a significant overall effect on mobile learning. Haili Qiao (2018) also pointed out some problems of MALT. For example, students with less self-control will use their smart phones to engage in other activities, such as chatting or playing online games. In addition, some students do not check the contents of the resources in detail, but download the resources simply to increase the experience points. So it is note-worthy that the favorable features of mobile devices, such as individualized interfaces, real-time access to information, instant communication and feedback, etc., are not sufficient conditions for positive learning effects. Therefore, researchers put forward a couple of suggestions to enhance the educational impact of MALT. Firstly, instructions should be designed more elaborately; secondly, longer intervention duration is needed; thirdly, reconciliation of the closer connection between hardware, software, teaching process and users is required (Yao-Ting Sung, 2016).

In summary, the previous research findings indicate the mobile assisted language teaching generates positive effect on improving English teaching quality. A large part of the research deals with study of literatures and a small part of the empirical research focuses on the attitudes toward MALT exploiting the instrument of questionnaires. However, experimental research which provides data that could possibly address how best to use MALT and the effectiveness of doing so is highly insufficient. Therefore, more empirical studies, particularly experimental ones are needed to confirm the efficacy of the use of MALT on language teaching quality. 


\section{RESEARCH DESIGN}

After a detailed literature review, this study decided to explore the role of mobile assisted instruction in improving the quality of English teaching by means of experiments.

\section{A. Research Questions}

This study attempted to answer the following questions: Does MALT effectively improve the quality of English teaching in higher vocational education? Does MALT effectively improve the teaching quality of English vocabulary, grammar, reading and writing respectively?

\section{B. Subjects and Research Tools}

The subjects were 30 sophomores in a vocational college, including 20 males and 10 females. The experiment used Moso Teach as a teaching platform. The experiential points obtained by students after completing tasks on the platform were taken as part of the research data, which were analyzed by SPSS17.

\section{Research Methods}

This study adopted the methods of literature research, experiment and quantitative analysis.

\section{Research Procedures}

The first stage of the experiment consisted of 8 weeks from the beginning of the term to the middle exam. Four units of the textbook were covered during that period, in which teachers used traditional teaching methods without the help of Moso Teach, including lecturing, giving paper-based home assignments and checking students' homework, etc. In the ninth week, a mid-term examination was held to examine students' learning effects in vocabulary, grammar, reading and writing. The test items of vocabulary are subjective, including translation, filling in blanks and making sentences, accounting for 50 points. Multiple choices, which were objective questions, were used to examine grammar and 20 grammar questions accounted for 20 points. Reading comprehension was made up of three articles, each with 5 multiple choice questions, altogether accounting for 30 points. In the writing part, students were asked to write a practical article, accounting for 20 points. The total score of the mid-exam paper was 120 .

The second stage of the experiment also lasted eight weeks from after the mid-exam to the end of the term and still four units were covered. While in the second period, the teacher used mobile assisted teaching approach, in which Moso Teach was employed as a platform. Teaching was carefully designed according to the net based English teaching strategies set by $\mathrm{Wu}$ (2017). In addition to the same classroom instruction as before the mid-term exam, micro lectures, PPT courseware and test questions, etc. were uploaded to the Moso Teach platform, and such learning activities as reading PPT, watching micro-lectures, brainstorming, discussion and self test, etc., were organized through Moso Teach. Students only finished their learning tasks given by their teachers on Moso Teach instead of doing traditional homework. Every time a student completed a learning task, he or she got the corresponding experience points. The final exam was held at the end of the second stage. Before that, the experiential points of each student were collected and input into SPSS 17 by researchers.

The same students, the same difficulty of learning content and the same teacher were used in the two phases of the experiment. And also, the mid-term exam and the final exam had the same test forms, the same quantity of questions, the same difficulty and the same scoring standard. All of the papers, whether they were of middle exam or final exam, were scored by the same teacher. The total scores and the scores for each particular skill were all input into SPSS 17 for quantitative analysis.

\section{RESULTS AND ANALYSIS}

The scores of mid-exam and final exam were obtained and the increased scores of the final exam compared to the mid-exam were calculated. The experiential points that students gained by participating in activities and completing tasks in Moso Teach were also collected. The whole set of data were input into SPSS 17 and then analyzed by paired sample t-test and correlation test so as to obtain the relationship between students' learning situation in Moso Teach and their learning result.

\section{A. The Difference in Scores between Middle and Final Exams}

The differences of students' scores between middle exam and final exam were detected using paired sample t-test. The result is as follows. 
TABLE I

THE DIFFERENCE IN SCORES BETWEEN MIDDLE AND FINAL EXAMS

\begin{tabular}{|c|c|c|c|c|c|}
\hline Items & Exams & Mean & $\mathrm{N}$ & $\begin{array}{l}\text { Paired Samples } \\
\text { Correlations }\end{array}$ & $\begin{array}{l}\text { Sig. (2-tailed) of Paired } \\
\text { Differences }\end{array}$ \\
\hline Total Score & Middle Exam & 86.13 & 30 & \multirow[t]{2}{*}{.959} & \multirow[t]{2}{*}{.000} \\
\hline & Final Exam & 92.10 & 30 & & \\
\hline Score of Vocabulary & Middle Exam & 36.93 & 30 & \multirow[t]{2}{*}{.927} & \multirow[t]{2}{*}{.000} \\
\hline & Final Exam & 38.80 & 30 & & \\
\hline Score of Grammar & Middle Exam & 14.17 & 30 & \multirow[t]{2}{*}{.952} & \multirow[t]{2}{*}{.000} \\
\hline & Final Exam & 16.27 & 30 & & \\
\hline Score of Reading & Middle Exam & 22.13 & 30 & \multirow[t]{2}{*}{.865} & \multirow[t]{2}{*}{.130} \\
\hline & Final Exam & 22.73 & 30 & & \\
\hline Score of Writing & Middle Exam & 12.90 & 30 & \multirow[t]{2}{*}{.864} & \multirow[t]{2}{*}{.000} \\
\hline & Final Exam & 14.30 & 30 & & \\
\hline
\end{tabular}

From table I, we can see that the final exam scores are higher than the middle exam in the total score and the scores of each item. The differences of all the items except reading comprehension have reached a significant level (Sig.<.05). This shows that the students' academic performance has been significantly improved after using Moso Teach, proving with data that MALT effectively improves the teaching quality, which is consistent with the research results of YaoTing Sung (2016), Khalitova et al. (2016) and Zhou (2017). Previous studies have also shown that the vast majority of students hold a positive attitude towards mobile learning, believing that mobile learning is more interesting, thus increasing their interest in learning. After completing a task, they can receive timely feedback and are therefore encouraged (Wang, 2018; Saidouni, et al., 2016; Ding, 2017). The convenience and the fun of using mobile terminals enable students to maintain a positive attitude towards mobile learning and eventually improve their academic performance.

\section{B. The Relation between Experience Value and Increased Scores}

TABLE II

THE CORRELATION BETWEEN EXPERIENCE POINTS AND INSCREASED SCORES

\begin{tabular}{|l|l|l|l|l|}
\hline Increase of Scores & Mean & Experience points (Mean=44.07) \\
\hline Item & 6.23 & .283 & Sig.(2-tailed) & N \\
\hline Increase of Total Score & 1.87 & .398 & .129 & 30 \\
\hline Increase of Vocabulary Score & 2.10 & -.296 & .029 & 30 \\
\hline Increase of Grammar Score & 0.60 & -.034 & .112 & 30 \\
\hline Increase of Reading Score & 1.40 & .232 & .860 & 30 \\
\hline Increase of Writing Score & & .217 \\
\hline
\end{tabular}

The correlation between the experience points and the increased score reflects the relationship between the situation of students' using Moso Teach and the degree of their learning progress. After calculation, the average experience value of the whole class is obtained which is 44.07, and then Pearson correlation is used to analyze the data. From Table II, we can see that the average total score of final exam is 6.23 points higher than that of the middle one. Although the correlation between the experiential points and the average increased total score has not reached a significant level, the correlation coefficient is .283, which is also a low correlation, thus to a certain extent indicating that the more students use Moso Teach, the greater their progress.

Obviously, the increased score of vocabulary is 1.87 , and the correlation coefficient between experience points and the increase of vocabulary score is .398 , which belongs to moderate correlation and reaches a significant level (Sig.<.05). The vocabulary item accounts for 50 points in the total test score which is 120, and has a large number of questions, including a complete set of subjective and objective ones, so the data are convincing to some extent. It shows that the students who frequently use Moso Teach have made remarkable progress in English vocabulary learning.

However, in grammar and reading, the relationship between the increased scores and the experiential points shows a negative correlation. This may be due to the fact that grammar questions are all objective multiple-choice questions, which not only have a single question type but also have a high probability of guessing scores. What is more, the grammar item accounts for only 20 points, which occupies a very low proportion of the total score, adding to the possibility that the data cannot accurately reflect the students' grammar learning effect. Reading comprehension requires a long period of knowledge accumulation and ability training to improve. It is impossible to achieve obvious results in a short time. Its progress has little to do with the knowledge learned in a short period. Besides, after investigation, it was found that in the second stage of teaching, the teacher did not set up reading comprehension tasks in the Moso Teach. On the one hand, it was relatively difficult to set up reading comprehension tasks, and it is hard for the teacher to control the students to finish these reading tasks conscientiously. On the other hand, reading comprehension needs to be improved gradually through the improvement of vocabulary, grammar and other comprehensive abilities. In addition, to a large extent, the experience points represent the quantity of tasks completed by the students and cannot reflect the quality of the tasks completed, that is, the experience value cannot fully reflect the degree to which the students have carefully used Moso Teach to learn.

\section{The Difference in Experience Value between Different Level Students}


The independent sample t-test was used to examine whether there were significant differences in the experiential points of students with different academic performance. The students are divided into three levels according to their final test results, namely three groups. The total score of the final exam is 120 . The first group is a group with high scores greater than or equal to 96 points. The second group is the middle score group with scores ranging from 72 ( inclusive ) to 95 ( inclusive ). The third group is a low score group with a score of less than 72 points. Statistics show that there are 12 students in the high score group with an average experience value of 47.92 . There are 16 middle level students with an average of 44.06. And 2 students belong to the low level group with an average experience value of 21. There is no significant difference between the variance of each group of samples, so the two-sample equal variance ttest is adopted. The significant level of difference in experiential values between the first and the second groups is .010, between the first and the third groups is .000 , and between the second and the third groups is .000. From the above data, it can be seen that the average experience value of students with high test scores and middle scores is evidently higher than that of students with low scores; the experience points of students in high, middle and low score groups are also ranked from high to low and the differences in experiential value between the three groups have reached significant levels. The above results show that the students with better academic performance use the mobile learning platform more frequently, which may be related to their good learning habits that they have developed over a long term. On the contrary, poor students have poor self-control ability and are prone to be interfered by entertainment software such as smart phone games. In addition, it is in agreement with the discovery of Al-Emran, et al. (2016) that lower level students employ learning strategies less than higher level students.

\section{CONCLUSION}

From the above analysis, it can be seen that mobile assisted language teaching has significantly improved the teaching quality of vocational college English. In addition, generally speaking, the quantity that students use the mobile teaching platform has a positive correlation with the degree of students' progress, i.e. the students who use the platform more have made greater progress. Therefore, it is suggested that teachers should actively employ mobile assisted language teaching approach. While teaching with MALT, teachers should elaborately and appropriately design their teaching. The resources uploaded should be practical as well as interesting, not too long or too large, suitable for fragmented learning. The learning tasks assigned by the teacher on the mobile platform should cover comprehensive English skills including listening, speaking, reading and writing so that students' English ability can be fully trained and improved. Teachers are also expected to adopt more effective measures to timely follow up the learning status and learning quality of students. If used properly, mobile assisted language teaching can be integrated successfully into a context of existing practices and beliefs. Besides, attention should be paid to the guidance and instruction for poor students in order to make them gradually see the interest and effectiveness of using mobile platforms and change their negative attitude towards mobile learning applications so that they can use mobile platforms more frequently to assist their English learning.

However, to a large extent, the experience value in this study reflects the quantity that students use the mobile assisted teaching platform, but not their learning quality, because a number of students may not study carefully and only click on the teaching resources, but they are still able to gain the experience points. In addition, in the middle and final exams, the items of grammar, reading and writing account for only a small proportion of the total score and have a single question type. As a result, no convincing data related to grammar, reading and writing were obtained in this experiment. Therefore it is suggested that in the future research the number and types of questions should be increased in grammar, reading and writing so as to further examine the impact that MALT has on those English knowledge and skills. Lastly, the number of samples in this study is relatively small, and the conclusions obtained need to be verified by a large number of samples in the future.

\section{REFERENCES}

[1] Al-Emran, M., H. M. Elsherif \& K. Shaalan. (2016). Investigating attitudes towards the use of mobile learning in higher education. Computers in Human behavior, 56, 93-102.

[2] Cavus, N. (2016). Development of an intelligent mobile application for teaching English pronunciation. Procedia Computer Science, 102, 365-369.

[3] China Industry Information Net. (2018). Analysis of mobile intelligent terminal size, APP development and development trend in the first quarter of 2017-2018 years of China.(n.d.). http://www.chyxx.com/industry/201807/655297.html (accessed 4/7/2018).

[4] Ding, M. M. (2017). A study on the status of college students' mobile learning based on smart phones. Unpublished master thesis, Nanchang University, Jiangxi, China.

[5] Guo, S. X. \& T. Guo. (2015). Research on the implementation strategies of public English teaching in higher vocational colleges based on WeChat. Journal of Jilin Teachers Institute of Engineering Technology, 31(7), 61-63.

[6] He, J. J. (2017). An exploration of college English micro mobile education based on APP. Time Education, 2017(21), 49-50.

[7] Khalitova, L. \& G. Gimaletdinova. (2016). Mobile technologies in teaching English as a foreign language in higher education: a case study of using mobile application Instagram. Paper presented at the 9th Annual International Conference of Education, Research and Innovation (iCERi), Seville, Spain.

[8] Liu, M., C. Navarrete \& J. Wivagg. (2014). Potentials of mobile technology for K-12 education: an investigation of iPod touch 
use for English language learners in the United States. Educational Technology \& Society (SI), 17(2), 115-126.

[9] Pan, J. X., Y. Z. Lei, L. L. Cheng \& H. Shi. (2010). Literature review in ubiquitous learning theory. Journal of Distance Education, 28(2), 93-98.

[10] Qiao, H. L. (2018). A brief discussion on course teaching reform of tourism policies and regulations. Journal of Heilongjiang Vocational Institute of Ecological Engineering, 31(1), 114-115.

[11] Saidouni, K. \& A. Bahloul. (2016). Teachers and students' attitudes towards using mobile-assisted language learning in higher education. Arab World English Journal (SI), 3, 123-140.

[12] Souza, C. F. (2015). Learning without distance: digital mobile technology within the teaching of English language. TextolivreLinguagem E Techologia, 8(1), 39-50.

[13] Su, D. R. \& Y. B. Li. (2016). Review of domestic M-learning in recent five years. China Educational Technology and Equipment, 2016(22), 8-10.

[14] Sung, Y. T., K. E. Chang \& T. C. Liu. (2016). The effects of integrating mobile devices with teaching and learning on students' learning performance: A meta-analysis and research synthesis. Computers \& Education, 94, 252-275.

[15] Wang, R. F. (2018). On the strategy of achieving efficient classes through mobile teaching. Vocational Education, 17(5), 48-50.

[16] Wu, R. (2017). A Study on SPOC assisted college oral English teaching strategies. Theory and Practice in Language Studies, 7(9), 756-763.

[17] Xu, Z. P., H. P. Li \& C. L. Wang. (2018). Application and research of mobile Internet technology and its applications in blended teaching based on Constructivism. Course Education Research, 2018(8), 239-240.

[18] Zhou, J. (2017). A research on the application of mobile learning in vocational college English teaching. Overseas English, $2017(24), 34-35$.

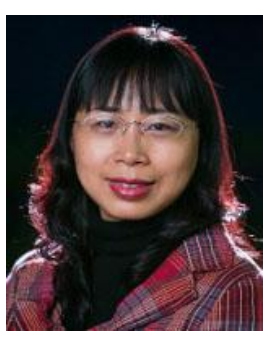

Rui Wu was born in Beijing, China in 1971. She received her M.A. Degree in applied linguistics from Beijing Institute of Technology, China in 2006. She is currently a lecturer in Beijing Information Technology College, China. Her academic research focuses on EFL teaching. 